\title{
PENGEMBANGAN APLIKASI MOBILE LEARNING PADA MATA KULIAH PEMROGRAMAN CLIENT SERVER UNTUK MENINGKATKAN PRESTASI BELAJAR MAHASISWA
}

\author{
Muhammad Sabir Ramadhan \\ Program Studi Teknik Informatika Fakultas Teknik Universitas Asahan \\ Jl. Jend. Ahmad Yani No. 1 Kisaran, 21224 \\ ramasabir@gmail.com
}

\begin{abstract}
This study aims to design interactive multimedia for computer client server programming with Androidbased so that it can be accessed via smartphone. Client server programming course is one of compulsory subjects in Informatics Engineering course. With the realization of multimedia is expected to shorten the learning time of students, and students can more easily understand the material of client server programming rather than through the tutorial tutorial as usual, and is expected to improve learning achievement. This multimedia realization chose to use the Android operating system to be accessible through smartphone that is currently widely used by the students. This interactive multimedia presents theories, simulations and problems as the evaluation of client server programming learning. The results of this interactive multimedia will be tested through the test instrument to the students on the study program of Informatika Technique of Asahan University. Instrument test used to know student achievement. Test instrument used is a questionnaire instrument to determine the quality of interactive multimedia computer network courses. Multimedia is designed using the main software such as Macromedia Flash, Macromedia Director, and Macromedia Authorware and Eclipse 4.2 along with supporting applications. The material to be delivered on interactive multimedia is tailored to the syllabus of client server programming courses on Strata 1 level. The expected research output is in the form of teaching materials for the enrichment of client server programming subjects and multimedia technology and will be socialized through the national seminar in the field of informatic engineering.
\end{abstract}

Keywords - interactive multimedia, Android, client server programming

\section{PENDAHULUAN}

Proses belajar mengajar merupakan suatu kegiatan melaksanakan kurikulum suatu lembaga pendidikan, agar dapat mempengaruhi para siswa mencapai tujuan pendidikan yang telah ditetapkan (Sudjana \& Rivai, 1997). Dalam proses belajar mengajar, diharapkan pendidik dapat menyampaikan materi yang diajarkan dan memberi fasilitas dalam belajar, seperti tanya jawab, sedangkan peserta didik dapat memahami materi yang diajarkan. Sehingga proses belajar mengajar dapat berjalan seperti yang diharapkan. Karena belajar itu penting sesuai dengan pendapat Nursalim, dkk (2007 yang berbunyi, "belajar merupakan kegiatan penting yang dilakukan setiap orang secara maksimal untuk dapat menguasai atau memperoleh sesuatu".

Faktor pendukung dalam proses belajar mengajar diantaranya adalah media pembelajaran. Media pembelajaran merupakan sarana bagi pendidik untuk menyampaikan materi dan mempermudah siswa dalam memahami materi yang diberikan. Dengan adanya media pembelajaran diharapkan proses belajar mengajar dapat berjalan dengan baik dan dapat membantu siswa lebih memahami materi.
Salah satu media pembelajaran yang menarik dan mudah diimplementasikan adalah mobile learning atau $\mathrm{m}$ - learning. Mobile learning/m-learning didefinisikan sebagai model pembelajaran yang memanfaatkan teknologi informasi dan komunikasi. Dalam hal ini khususnya memanfaatkan peralatan IT genggam dan bergerak seperti PDA, telepon genggam, smartphone ataupun tablet PC (Quinn, 200).. Terdapat tiga fungsi mobile learning dalam kegiatan pembelajaran di dalam kelas (classroom instruction), yaitu sebagai suplemen (tambahan), yang sifatnya pilihan (opsional), pelengkap (komplemen), atau pengganti (substitusi).

1. Suplemen (tambahan)

Mobile Learning berfungsi sebagai suplement (tambahan), sekalipun sifatnya opsional, peserta didik yang memanfaatkannya tentu akan memiliki tambahan pengetahuan atau wawasan.

2. Komplemen (pelengkap)

Mobile learning berfungsi sebagai komplemen (pelengkap), yaitu: materinya diprogramkan untuk melengkapi/reinforcement materi pembelajaran yang diterima peserta didik di dalam kelas.

3. Substitusi (pengganti)

Beberapa perguruan tinggi di negara-negara maju memberikan beberapa alternatif model kegiatan pembelajaran kepada para peserta didik /siswanya. Tujuannya agar para peserta didik dapat secara fleksibel mengelola kegiatan perkuliahannya 
sesuai dengan waktu dan aktifitas sehari-hari peserta didik.

Salah satu perkembangan teknologi informasi dan komunikasi yang saat ini sedang berkembang pesat adalah smartphone dengan sistem operasi Android. Android merupakan sistem operasi terbuka yang diperuntukkan untuk mobile device atau smart phone yang saat ini sedang sangat diminati oleh masyarakat. Android merupakan salah satu sistem operasi berbasis Linux yang bersifat open source yang dapat digunakan di perangkat mobile. Tujuan utama dari sistem operasi Android adalah untuk memajukan inovasi-inovasi piranti telepon bergerak agar pengguna mampu menikmati hasil eksplorasi dari kemampuan mobile sistem operasi Android dibandingkan dengan sistem operasi mobile lainnya.

Mata kuliah pemrograman client server merupakan salah satu mata kuliah wajib pada program studi Teknik Informatika. Mata kuliah pemrograman client server merupakan salah satu mata kuliah yang sangat penting pada bidang teknik informatika. Oleh karena itu, pemahaman mahasiswa terhadap materi pemrograman client server amatlah penting untuk melengkapi materimateri lainnya. Biasanya dosen akan menyampaikan materi melalui ceramah, diskusi atau dengan bantuan slide. Penyampaian materi dengan cara-cara tersebut menimbulkan permasalahan di antaranya mahasiswa kurang memahami materi yang disampaikan dosen. Hal ini bisa saja disebabkan oleh kurang menariknya dosen dalam menyampaikan materi atau bisa juga dikarenakan keterbatasan sarana-prasarana yang mendukung. Di dunia maya materi mengenai pemrograman client server teori maupun praktek telah banyak ditemui, tetapi untuk materi dalam bentuk mobile learning belum terlalu banyak. Materi yang dapat diakses melalui smartphone berbasis Android juga belum ditemukan.

Dengan melihat uraian di atas, maka rumusan masalah yang diangkat adalah bagaimana merancang dan membangun suatu media pembelajaran dalam bentuk mobile dan interaktif serta menarik sehingga membantu mahasiswa memahami materi pemrograman client server dengan lebih mudah dan bagaimamana memanfaatkan sistem operasi Android sehingga aplikasi m-learning ini dapat dijalankan pada smartphone sehingga dapat dipelajari dimana dan kapan saja tanpa dibatasi ruang dan waktu.

Tujuan penelitian ini adalah merancang dan membangun media pembelajaran dalam bentuk aplikasi mobile learning untuk mata kuliahn pemrograman web berbasis sistem operasi Android sehingga dapat diakses pada smartphone kapan saja tanpa dibatasi ruang dan waktu dan juga diharapkan dapat meningkatkan kinerja dosen dalam mengajar mata kuliah pemrograman client server.

\section{METODE PENELITIAN}

Metode yang akan digunakan pada penelitian ini sebagai berikut:

a. Studi Pustaka (literatur)

Studi pustaka (literatur) dimaksudkan sebagai sumber pelengkap yang berhubungan dengan masalah penelitian. Pengumpulan data dilakukan dengan cara membaca literatur yang berhubungan dengan masalah yang diteliti.

b. Pengembangan Sistem

Dalam tahap pengembangan perangkat lunak digunakan metode Waterfall yaitu sebuah model pengembangan perangkat lunak dilakukan secara sekuensial, dimana satu tahap dilakukan setelah tahap sebelumnya selesai dilaksanakan (Gambar 1).

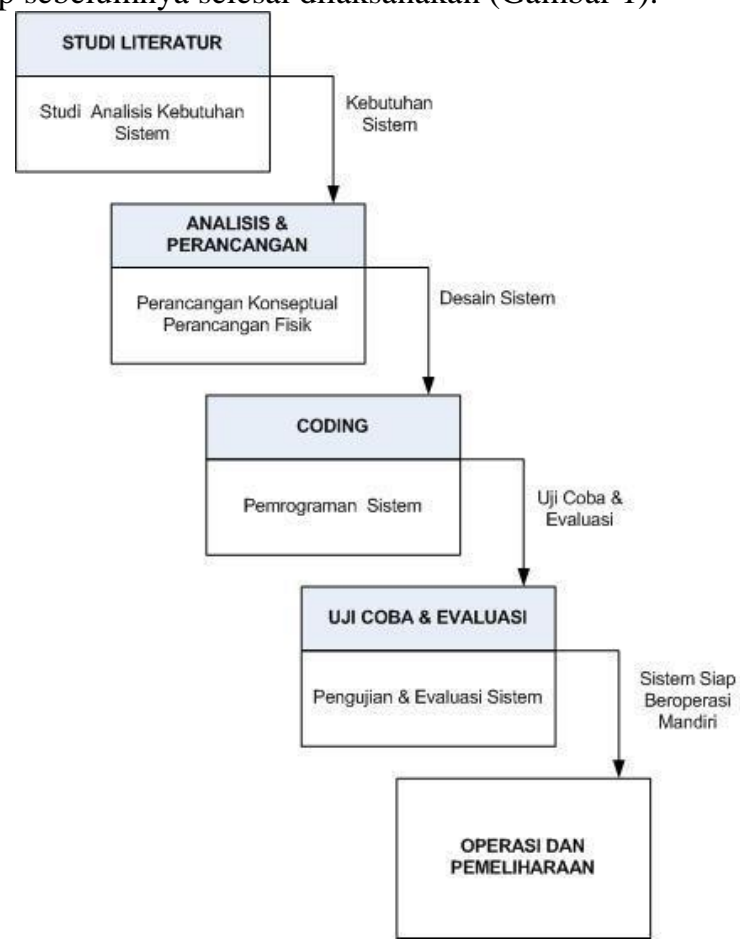

Gambar 1. Metode Waterfall

Adapun model ini dimulai dari tahap :

a. Analysis, pada tahap ini dilakukan dengan menganalisa data sesuai kebutuhan sistem yang kemudian akan diolah berdasarkan kebutuhan sistem itu sendiri.

b. Design, pada tahap ini melakukan perancangan arsitektur sistem, use case diagram, diagram activity, struktur database, relasi database dan rancangan menu-menu.

c. Coding, pada tahap ini merupakan proses mengubah desain menjadi bentuk yang dapat dimengerti oleh komputer yaitu dengan menggunakan bahasa pemrograman yang 
dipilih.

d. Testing, pada tahap ini melakukan pengujian pada perangkat lunak, Tahap pengujian sistem ini bertujuan untuk menguji sistem yang telah dibangun atau memperbaiki jika mungkin masih terdapat kekurangan.

e. Implementation, tahap ini merupakan tahap akhir dari pengembangan aplikasi setelah dapat melalui tahap testing. Hasil perancangan dengan bahasa pemrograman yang nantinya akan digunakan pada penerapan sistem.

\section{HASIL DAN PEMBAHASAN}

1. Perangkat Keras \& Perangkat Lunak Yang Digunakan

Perangkat Keras yang digunakan adalah :

a. Satu unit komputer dengan spesifikasi minimum sebagai berikut :

- Prosessor Intel Core i3-2410M CPU $2.30 \mathrm{GHz}$

- $\quad$ RAM (Random Access Memory) 4 GB

- VGA (Video Graphics Adapter) $1 \mathrm{MB}$

- $\quad$ Piranti masukan berupa mouse dan keyboard

- $\quad$ Piranti keluaran berupa monitor

- Media penyimpanan seperti harddisk dengan kapasitas $320 \mathrm{~GB}$

b. Satu unit smartphone berbasis sistem operasi Android untuk menjalankan program aplikasi dengan spesifikasi minimum sebagai berikut :

- $\quad$ Sistem Operasi : Android Jelly Bean v4.3

- $\quad$ CPU : Intel Atom CPU Z2560 1.60 GHz.

- Memori internal : $2 \mathrm{~GB}$

- Display: 720 x 1280 pixels, 5 inches

- Piranti masukkan : Touch screen capacitive

- Kabel Data/Wifi

Perangkat Lunak yang digunakan adalah :

- $\quad$ Sistem Operasi Microsoft Windows 7

- Android Software Development Kit (SDK) versi 1.8 ,

- Eclipse versi Juno

- Appserv

- PHP

- MySQL

- Dreamweaver

\section{Arsitektur Sistem}

Arsitektur sistem mobile learning mata kuliah pemrograman client server adalah sistem client server (Gambar 2). Arsitektur sistem yang digunakan dalam penelitian ini adalah client server yaitu desain sebuah aplikasi yang terdiri dari client dan server yang saling berkomunikasi ketika mengakses server dalam suatu jaringan

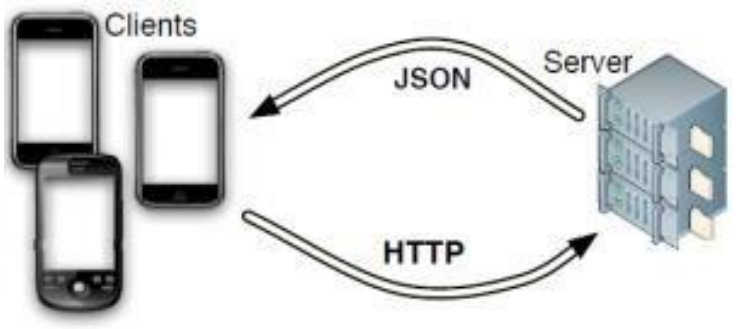

Gambar 2. Arsitektur Client server

. Client merupakan sembarang sistem atau proses yang melakukan suatu permintaan data atau layanan ke server, sedangkan server ialah sistem atau proses yang menyediakan data atau layanan yang diminta oleh client.

\section{Use Case Diagram}

Use case diagram merupakan gambaran yang diharapkan dari sebuah sistem. Sebuah use case mempresentasikan sebuah hubungan atau interaksi antara pengguna dengan sistem. Gambar 3 menunjukkan usecase diagram dari aplikasi $m$ - learning mata kuliah pemrograman client server berbasis Android.

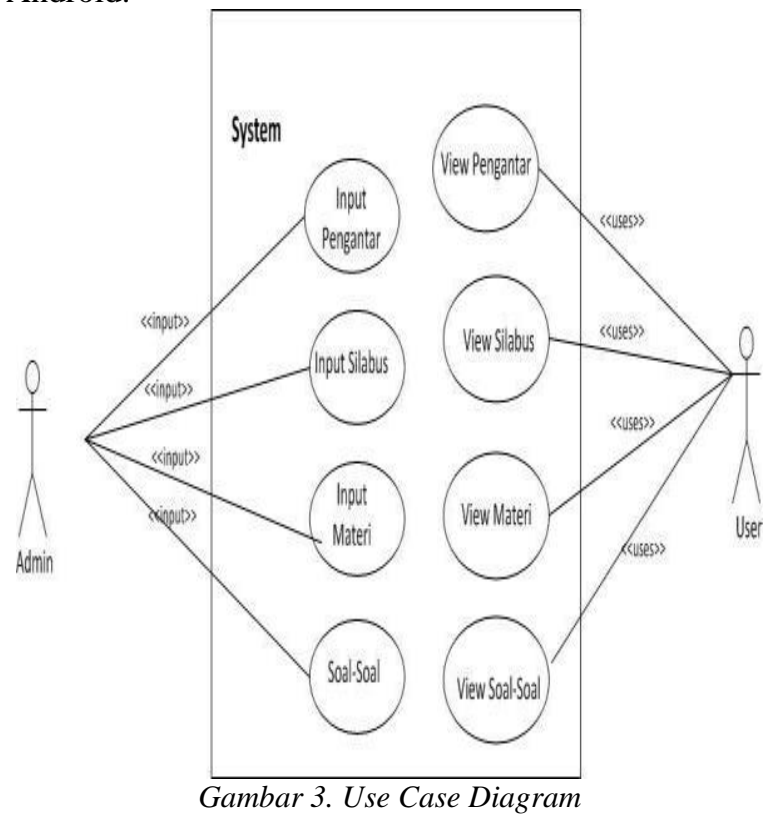

\section{Activity Diagram}

Activity diagram menggambarkan berbagai alir aktivitas dalam sistem yang sedang dirancang, bagaimana masing-masing alir berawal, decision yang mungkin terjadi, dan bagaimana mereka berakhir. Activity diagram juga dapat menggambarkan sebuah proses paralel yang mungkin terjadi pada beberapa eksekusi. Activity diagram aplikasi pemrograman client server berbasis android menggambarkan berbagai alir 
aktivitas dalam sistem yang sedang dirancang, bagaimana masing-masing alir berawal, decision yang mungkin terjadi dan bagaimana mereka berakhir. Gambar 4 memperlihatkan activity diagram dari aplikasi m-mobile mata kuliah pemrograman client server.

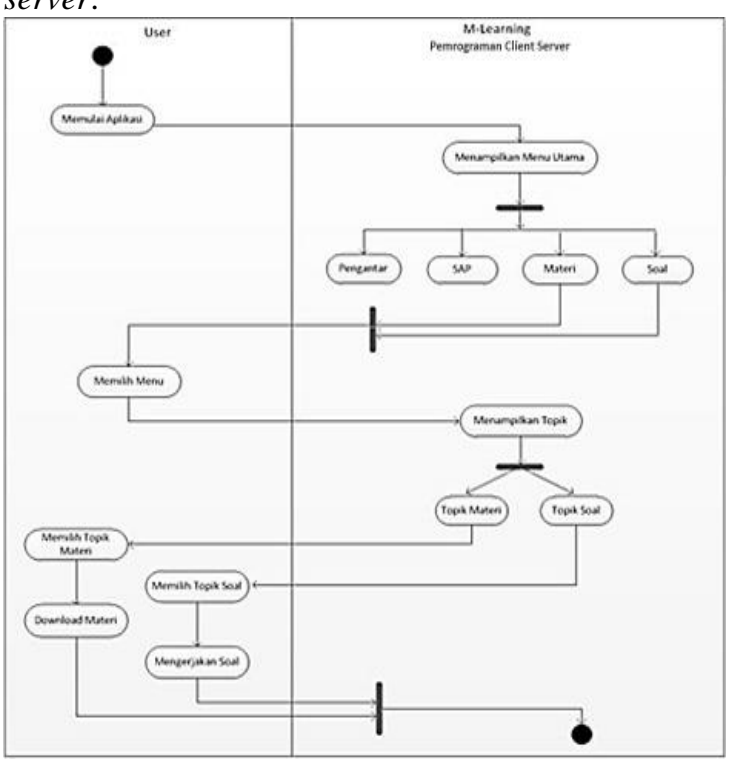

\section{Acivity Diagram}

\section{HIPO (Hierarchyplus Input-Proses-Output)}

HIPO (Hierarchyplus Input-Proses-Output) merupakan metodologi yang dikembangkan dan didukung oleh IBM. HIPO adalah alat dokumentasi program, yang digunakan sebagai alat desain dan teknik dokumentasi dalam siklus pengembangan sistem. Gambar 5 menunjukkan Visual Tabel of Contents (VTOC) untuk m-learning mata kuliah pemrograman client server pada back end system dan Gambar 6 menunjukkan VTOC untuk front end system.

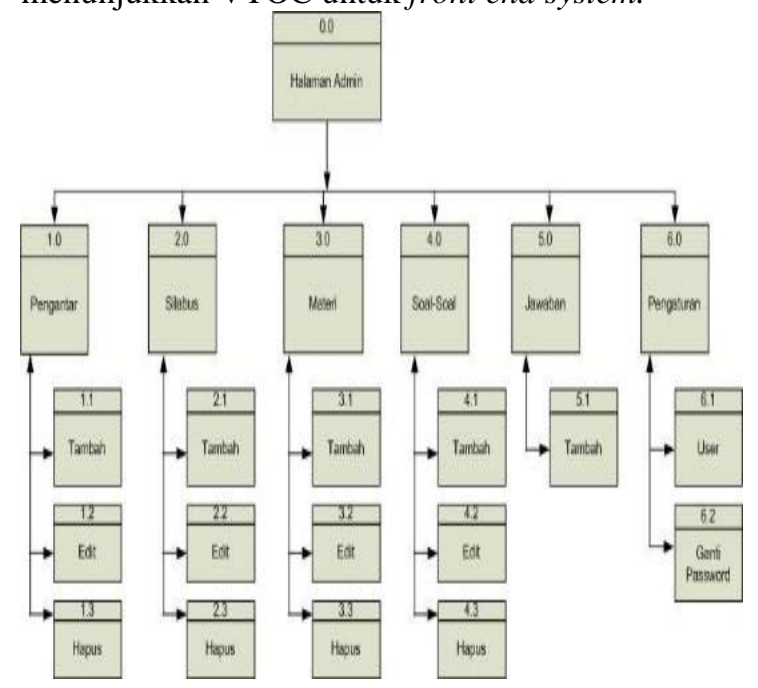

Gambar 5. VTOC Back End SystemGambar

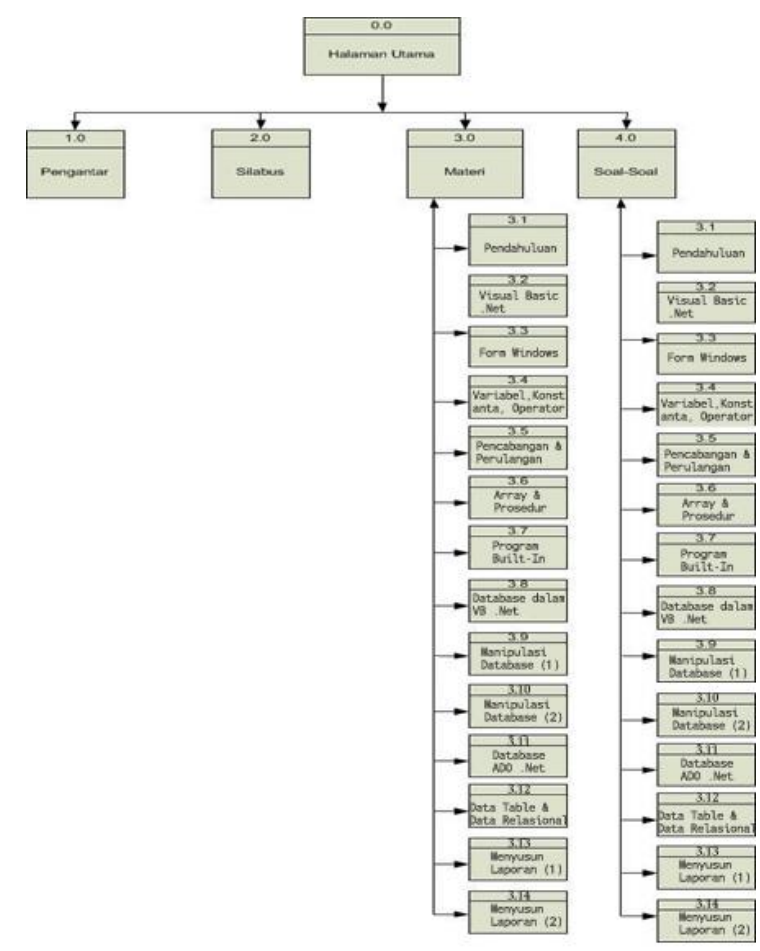

Gambar 6. VTOC Front End System

6. Struktur Database

Struktur database aplikasi pembelajaran ini dirancang menjadi 7 tabel yaitu :

1. Tabel user

2. Tabel topik

3. Tabel tbl_soal

4. Tabel sap

5. Tabel materi

6. Tabel jawaban

7. Tabel m_content

1. Tabel User

Tabel ini berfungsi untuk merekam data-data user. Tabel 1. Perancangan Struktur Tabel User

\begin{tabular}{|c|c|c|c|c|}
\hline No & Field & Type & Size & Keterangan \\
\hline 1 & Id_User & Int & 5 & $\begin{array}{l}\text { - Primary Key } \\
\text { - Id untuk setiap user }\end{array}$ \\
\hline 2 & Username & Varchar & 25 & - Nama user \\
\hline 3 & Password & varchar & 50 & - Password \\
\hline 4 & Nama & varchar & 50 & - Nama user \\
\hline 5 & Jabatan & varchar & 35 & - Jabatan user \\
\hline 6 & E-Mail & varchar & 50 & - Email user \\
\hline 7 & Foto & varchar & 50 & - Foto user \\
\hline
\end{tabular}


2. Tabel Topik

Tabel ini berfungsi untuk merekam data-data topik materi pembelajaran.

Tabel 2. Perancangan Struktur Tabel Topik

\begin{tabular}{|c|c|c|c|c|}
\hline $\mathrm{No}$ & Field & Type & Size & Keterangan \\
\hline 1 & Id_topik & Int & 5 & $\begin{array}{l}\text { - Primary key } \\
\text { - Id untuk setiap topik }\end{array}$ \\
\hline 2 & Topik & Varchar & 50 & - Topik \\
\hline 3 & Id_parent & int & 3 & - Id parent \\
\hline
\end{tabular}

\section{Tabel Tbl_Soal}

Tabel ini berfungsi untuk merekam data-data soal.

Tabel 3. Perancangan Struktur Tabel Tbl_Soal

\begin{tabular}{|l|l|l|l|l|}
\hline No & Field & Type & Size & \multicolumn{1}{|c|}{ Keterangan } \\
\hline 1 & Id_soal & Int & 5 & $\begin{array}{l}\bullet \text { Primary key } \\
\bullet \text { Id untuk setiap soal }\end{array}$ \\
\hline 2 & soal & Text & 5 & $\begin{array}{l}\bullet \text { Foreign Key } \\
\bullet \text { Id merk kendaraan }\end{array}$ \\
\hline 3 & A & Text & & $\bullet$ Jawaban A \\
\hline 4 & B & Text & & $\bullet$ Jawaban B \\
\hline 5 & C & Text & & $\bullet$ Jawaban C \\
\hline 6 & D & Text & & $\bullet$ Jawaban D \\
\hline 7 & E & Text & & $\bullet$ Jawaban E \\
\hline 8 & jawaban & int & 2 & $\bullet$ Kunci jawaban \\
\hline 9 & Id_topik & int & 3 & $\bullet$ Nama tipe kendaraan \\
\hline
\end{tabular}

\section{Tabel SAP}

Tabel ini berfungsi untuk merekam data-data SAP (Satuan Acara Perkuliahan).

\begin{tabular}{|l|l|l|l|l|}
\multicolumn{1}{|c|}{ Tabel 4. Perancangan Struktur Tabel SAP } \\
\hline No & Field & Type & Size & \multicolumn{1}{|c|}{ Keterangan } \\
\hline 1 & Id_SAP & Int & 5 & $\begin{array}{l}\bullet \text { Primary key } \\
\bullet \text { Id untuk setiap } \\
\text { jenis SAP }\end{array}$ \\
\hline 2 & SAP & Varchar & 25 & $\bullet$ Nama materi \\
\hline 3 & File & & & $\bullet$ File Materi SAP \\
\hline
\end{tabular}

\section{Tabel Materi}

Tabel ini berfungsi untuk merekam data-data materi pembelajaran mata kuliah pemrograman client server.

Tabel 5. Perancangan Struktur Tabel Materi

\begin{tabular}{|c|l|l|l|l|}
\hline No & \multicolumn{1}{|c|}{ Field } & \multicolumn{1}{|c|}{ Type } & Size & \multicolumn{1}{|c|}{ Keterangan } \\
\hline 1 & Id_materi & Int & 3 & $\begin{array}{l}\bullet \text { Primary key } \\
\bullet \text { Id untuk setiap } \\
\text { materi }\end{array}$ \\
\hline 2 & Materi & Varchar & 100 & $\bullet$ Judul materi \\
\hline 3 & File_nama & varchar & 200 & $\bullet$ File materi \\
\hline 4 & Id_topik & int & 3 & $\begin{array}{l}\bullet \text { Foreign key } \\
\bullet \text { Id untuk setiap } \\
\text { topik }\end{array}$ \\
\hline 5 & ext & varchar & 15 & $\bullet$ Jenis extensi file \\
\hline
\end{tabular}

6. Tabel Jawaban

Tabel ini berfungsi untuk merekam data-data jawaban.

Tabel 6. Perancangan Struktur Tabel Jawaban

\begin{tabular}{|l|l|l|l|l|}
\hline No & \multicolumn{1}{|c|}{ Field } & \multicolumn{1}{|c|}{ Type } & Size & \multicolumn{1}{|c|}{ Keterangan } \\
\hline 1 & Id_jawaban & Int & 5 & $\begin{array}{l}\bullet \text { Primary key } \\
\text { Id untuk setiap } \\
\text { jawaban soal } \\
\text { yang telah } \\
\text { dikerjakan }\end{array}$ \\
\hline 2 & Tanggal & datetime & $\begin{array}{l}\bullet \text { Tanggal } \\
\text { mengerjakan soal }\end{array}$ \\
\hline 3 & Ip & varchar & 25 & $\begin{array}{l}\bullet \text { IP address bagi } \\
\text { user yang } \\
\text { mengerjakan soal }\end{array}$ \\
\hline 4 & Nama & varchar & 25 & $\begin{array}{l}\bullet \text { Nama user yang } \\
\text { mengerjakan soal }\end{array}$ \\
\hline 5 & Topik & varchar & 200 & $\begin{array}{l}\bullet \text { Topik soal yang } \\
\text { dikerjakan }\end{array}$ \\
\hline 6 & Total & int & 3 & $\begin{array}{l}\bullet \text { Jumlah soal yang } \\
\text { dikerjakan }\end{array}$ \\
\hline 7 & Benar & int & 3 & $\begin{array}{l}\bullet \text { Jumlah jawaban } \\
\text { yang benar }\end{array}$ \\
\hline 8 & Salah & int & 3 & $\begin{array}{l}\bullet \text { Jumlah jawaban } \\
\text { yang salah }\end{array}$ \\
\hline
\end{tabular}

7. Tabel m_content

Tabel ini berfungsi untuk menyimpan isi dari menu Pengantar.

Tabel 7. Perancangan Struktur Tabel m_content

\begin{tabular}{|c|l|l|l|l|}
\hline No & Field & Type & Size & Keterangan \\
\hline 1 & Id_content & Int & 3 & $\begin{array}{l}\bullet \text { Primary key } \\
\bullet \text { Id untuk setiap pengantar }\end{array}$ \\
\hline 2 & Judul & & & $\bullet$ Judul pengantar \\
\hline 3 & Content & & & $\bullet$ Isi pengantar \\
\hline
\end{tabular}

7. Implementasi Sistem

a. Menu Utama Sistem

Menu utama menu mobile learning mata kuliah pemrograman client server dapat dilihat pada gambar 7. Menu-menu yang ada pada sistem ini adalah : 


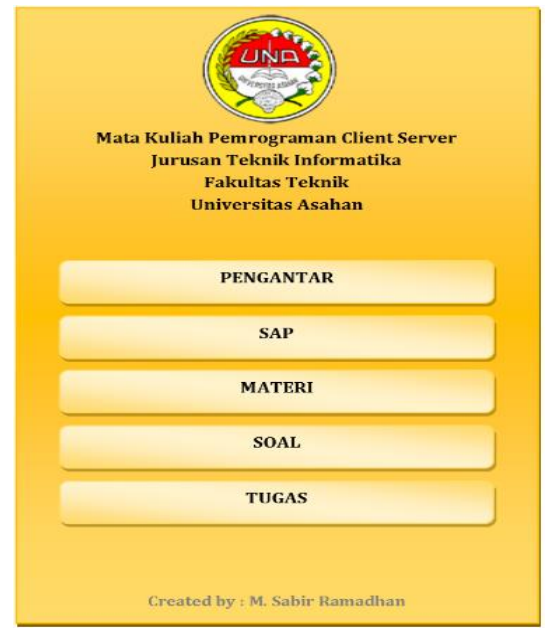

Gambar 7. Mепu Utama Sistem

b. Menu Pengantar

Menu Pengantar yang berisi petunjuk penggunaan aplikasi mobile learning.

c. Menu SAP (Satuan Acara Perkuliahan)

Menu SAP yaitu menu yang berisi SAP (Satuan Acara Perkuliahan) mata kuliah pemrograman client server dalam

d. Menu Materi

Menu Materi dipisah berdasarkan topik-topik materi sesuai Satuan Acara Perkuliahan. User bisa memilih topik yang diinginkan. Setelah memilih topik yag diinginkan masih ada sub topik lagi, baru kemudian isi materi dari sub topik tersebut (gambar 8, 9, 10 dan 11).

\begin{tabular}{|rl|}
\hline KEmbali & \multicolumn{1}{|c|}{ PEMROGRAMAN CLIENT SERVER } \\
\hline MATERI & \\
\hline 1. & Pendahuluan \\
2. & Visual Basic .Net \\
3. & Form Windows \\
4. & Variabel, Konstanta, Operator \\
5. & Pencabangan \& Perulangan \\
6. & Array \& Prosedur \\
7. & Program Built-In \\
8. & Database dalam VB .Net \\
9. & Manipulasi Database (1) \\
10. & Manipulasi Database (2) \\
11. & Database ADo .Net \\
12. & Data Table \& Data Relasional \\
13. & Menyusun Laporan (1) \\
14. & Menyusun Laporan (2) \\
\hline
\end{tabular}

Gambar 8. Menu Materi

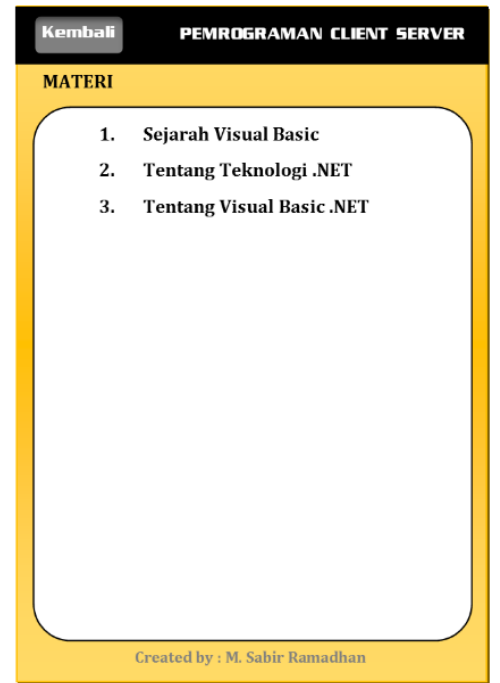

Gambar 9. Sub Menu Materi

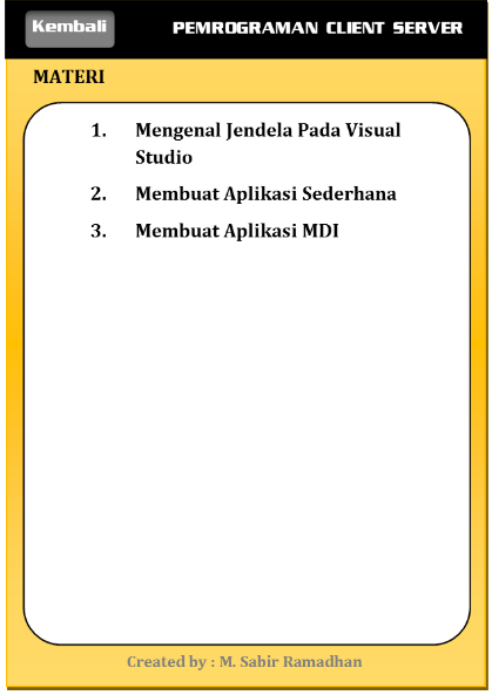

Gambar 10. Sub Sub Materi

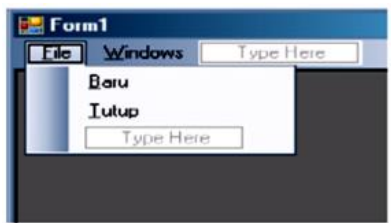

\begin{tabular}{|l|l|l|}
\hline File & Edik Windows \\
\hline Baru & \\
\hline Tutup & Rich Text Box \\
\hline & & Data Pribadi \\
\hline
\end{tabular}

Gambar 11. Isi materi sesuai topik yang dipilih

d. Menu Soal

Menu Soal berisi soal-soal yang dapat dipilih sesuai topik yang diinginkan. Soal dalam bentuk pilihan berganda (Gambar 12). Setelah selesai mengerjakan soal akan langsung muncul jumlah 
jawaban yang benar dan jumlah jawaban yang salah (Gambar 13).

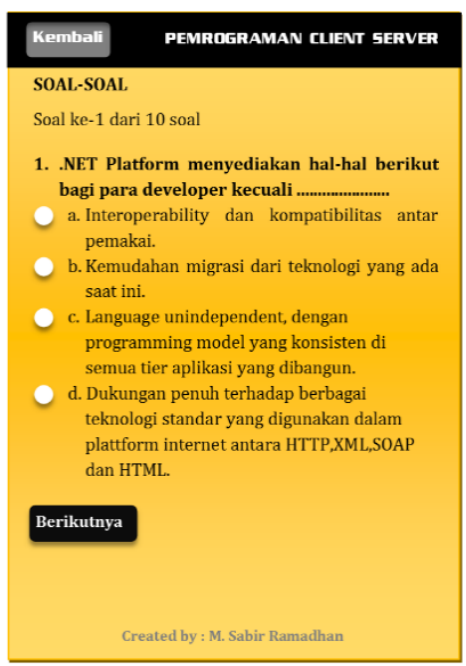

Gambar 12. Menu Soal

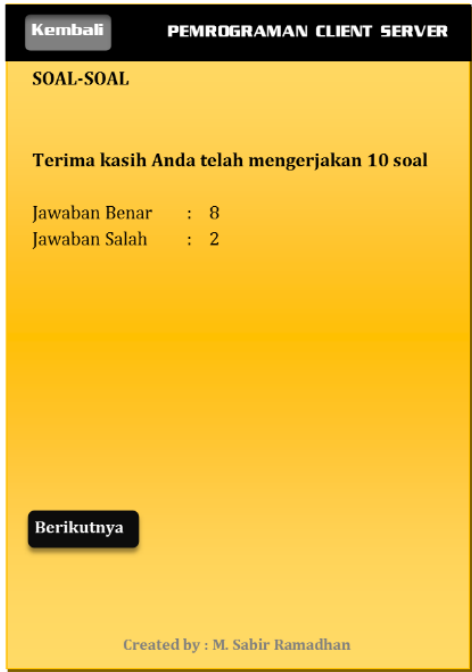

Gambar 13. Hasil Mengerjakan Soal

e. Menu Admin

Menu Admin digunakan untuk mengelola data-data sistem, menu admin terdiri dari:

a. Content yang digunakan untuk mengelola data-data Pengantar, SAP dan Materi.

b. Jawaban yang digunakan utnuk merekap jawaban-jawaban soal dari mahasiswa.

c. Master, digunakan untuk mengelola datadata topik dan soal-soal.

d. Pengaturan, digunakan untuk mengganti password.

\section{Uji Coba Aplikasi}

Ada beberapa hal yang akan dijabarkan dalam hasil uji coba aplikasi ini, yaitu sebagai berikut :
1. Teknik yang Digunakan

Teknik yang digunakan pada uji coba aplikasi ini dibagi menjadi 2 dasar teknik. Yaitu teknik uji coba berdasarkan versi sistem operasi Android dan teknik uji coba berdasarkan ukuran display atau layar smartphone.

2. Tempat Pelaksanaan Uji Coba Aplikasi ini diujicobakan pada beberapa smartphone yang memiliki beberapa macam sistem operasi Android dan ukuran display atau layar, yang dilakukan dengan cara uji coba instalasi aplikasi di dalam smartphone berdasarkan versi sistem operasi dan ukuran layar dari yang kecil sampai yang berukuran lebar.

3. Hasil Uji Coba Aplikasi

Hasil uji coba terhadap dua teknik yang digunakan adalah sebagai berikut :

a. Teknik uji coba berdasarkan versi sistem operasi Android. Untuk teknik ini dilakukan uji coba terhadap 8 (delapan) versi Android yaitu :

Tabel 8. Versi Android Yang Digunakan untuk uji coba aplikasi

\begin{tabular}{|c|c|c|}
\hline No & Versi Android & $\begin{array}{l}\text { Smartphone Yang } \\
\text { Digunakan }\end{array}$ \\
\hline 1 & Android 1.5 Cupcake & $\begin{array}{ll}\text { Samsung } & \text { Galaxy } \\
17500 & \end{array}$ \\
\hline 2 & Android 1.6 Donut & HTC Tattoo \\
\hline 3 & Android 2.02.1 Eclair & Samsung Corby i5500 \\
\hline 4 & Android 2.2 Froyo & $\begin{array}{l}\text { Samsung Galaxy Mini } \\
\text { GT-S5570 }\end{array}$ \\
\hline 5 & $\begin{array}{l}\text { Android } 2.2 \\
\text { Gingerbread }\end{array}$ & Motprola Droid X \\
\hline 6 & $\begin{array}{l}\text { Android } \\
\text { Honeycomb }\end{array}$ & Acer Iconia Tab A500 \\
\hline 7 & Android 4.0 Ice Cream & $\begin{array}{lll}\text { Ainol Novo } & \text { Flame } \\
\text { Tablet } & & \\
\end{array}$ \\
\hline 8. & $\begin{array}{l}\text { Android 4.1-4.2 Jelly } \\
\text { Bean }\end{array}$ & $\begin{array}{l}\text { SAMSUNG } \\
\text { Galaxy S III }\end{array}$ \\
\hline
\end{tabular}

Dari hasil uji coba implementasi terhadap 8 versi Android yang berbeda seperti Tabel 8 di atas diperoleh hasil bahwa aplikasi ini dapat berjalan dengan baik mulai versi Android 2.2 ke atas atau Froyo ke atas.

b. Teknik uji coba berdasarkan ukuran display atau layar smartphone.

Untuk teknik ini, hasil uji coba dapat dilihat pada Tabel 9 berikut: 
Tabel 9. Tabel Uji Coba Berdasarkan Ukuran Layar Smartphone

\begin{tabular}{|c|c|c|}
\hline $\begin{array}{c}\text { Contoh } \\
\text { Smartphone }\end{array}$ & $\begin{array}{c}\text { Ukuran Display } \\
\text { Smartphone }\end{array}$ & $\begin{array}{c}\text { Running } \\
\text { Aplikasi }\end{array}$ \\
\hline $\begin{array}{c}\text { Samsung } \\
\text { Galaxy Mini }\end{array}$ & QVGA $(240 \times 320)$ & OK \\
\hline $\begin{array}{c}\text { Samsung } \\
\text { Galaxy Ace }\end{array}$ & HVGA $(320 \times 480)$ & OK \\
\hline $\begin{array}{c}\text { Motorola } \\
\text { Droid X }\end{array}$ & WVGA $(480 \times$ & OK \\
\hline Ainol Novo & HD $(720 \times 1280)$ & OK \\
Flame Tablet & & \\
\hline
\end{tabular}

KESIMPULAN

Kesimpulan

Dari hasil kegiatan penelitian yang telah dilakukan dapat ditarik beberapa kesimpulan, yaitu :

1. Telah dapat dirancang sebuah sistem yang menghasilkan aplikasi mobile learning untuk pembelajaran mata kuliah pemrograman client server dapat berjalan diatas sistem operasi Android dan dengan arsitektus sistem adalah client server sehingga data dapat diperbaharui kapan saja sesuai kebutuhan.

2. Materi-materi yang disampaikan dalam aplikasi ini dalam bentuk file pdf dan format video mp4.

3. Aplikasi yang dihasilkan dibuat dengan beberapa dukungan perangkat lunak yaitu Java Development Kit (JDK) versi 6, Eclipse versi Juno, Appserv, PHP, MySQL sebagai alat bantu dalam mengembangkan aplikasi berbasis Android.

4. Setelah dilakukan uji coba, aplikasi ini dapat berjalan baik pada sistem operasi Android mulai versi 2.2 ke atas dan dapat ditampilkan dengan baik pula di berbagai ukuran layar smartphone.

\section{SARAN}

Pembuatan aplikasi mobile learning mata kuliah pemrograman client server berbasis Android ini bertujuan untuk memberikan kemudahan kepada user khususnya mahasiswa dalam mempelajari materi mengenai pemrograman client server secara lengkap dan jelas. Untuk itu penulis memberikan saran dalam upaya meningkatkan kualitas dan mengembangkan aplikasi ini :

1. Mobile learning ini akan lebih menarik jika dilengkapi dengan materi yang berbasis multimedia interaktif atau dalam bentuk animasi.

2. Mobile learning ini dapat dikembangkan dengan menambah beberapa menu seperti forum diskusi dan menu mengirim tugas.

3. Mobile learning ini dapat dikembangkan ke mata kuliahliah yang lainnya sehingga nanti akhirnya dapat menjadi sebuah mobile learning yang lengkap.

\section{DAFTAR PUSTAKA}

[1] Mulyadi, 2010, Membuat Aplikasi Untuk Android, Multimedia Center Publishing, Yogyakarta

[2] Pressman, R., 2002, Rekayasa Perangkat Lunak Pendekatan Praktisi, Andi Offset, Yogyakarta.

[3] Safaat, 2011, Pemrograman Aplikasi Mobile Smartphone dan Tablet PC Berbasis Android, Bandung, Informatika.

[4] Tri Listyorini dan Anteng Widodo, 2013, Perancangan Mobile Learning Mata Kuliah Sistem Operasi Berbasos Android, Jurnal Simetris, Volume 3, Nomor 1, Aoktober 2014.

[5] Yudhistira, Y., 2011, Membuat Aplikasi iPhone, Android dan Blackberry, PT. Transmedia, Jakarta.

[6] Zaki, A., 2012, Membuat Web Mobile dengan jQuery Mobile, PT. Elek Media Komputindo, Jakarta. 